\title{
Perceived discomfort of shoulder and elbow postures with external loads
}

\author{
Seokhee Na*1, Dongjin Kim ${ }^{1}$, Gukmu Park ${ }^{1}$, Dohyung Kee ${ }^{2}$, Min K. Chung ${ }^{1}$ \\ ${ }^{1}$ Department of Industrial and Management Engineering, Pohang University of Science and \\ Technology, Pohang, Korea \\ ${ }^{2}$ Department of Industrial and Systems Engineering, Keimyung University, Daegu, Korea \\ *na@postech.ac.kr
}

\begin{abstract}
The objective of this study is to investigate the perceived discomfort for the external load added postures which are combined with shoulder flexion/extension and elbow flexion. 12 healthy male undergraduate and graduate students participated in this experiment. Independent variables were the shoulder flexion/extension angle $\left(-20^{\circ}, 0\right.$, $\left.45^{\circ}, 90^{\circ}, 135^{\circ}\right)$, the elbow flexion angle $\left(0,45^{\circ}, 120^{\circ}\right)$, and the external load $(0,1.5 \mathrm{Kg}, 3 \mathrm{Kg})$. Dependent variable was a whole body perceived discomfort using Borg's CR10. The subjects rated the perceived discomfort after they had maintained the given posture for 60 seconds. The ANOVA results showed that main factors and three two-way interactions were statistically significant at $\alpha=0.05$. The regression analyses were performed to quantify the effect of external loads on the perceived discomfort. The perceived discomfort linearly increased as the external loads increased. The effect of the external loads to the perceived discomfort was quantified and classified into three levels based on the result of regression analyses.
\end{abstract}

Keywords: Shoulder and elbow posture; External loads; Perceived discomfort

\section{Introduction}

The number of the injured workers with work-related musculoskeletal disorders (WMSDs) in Korea has increased considerably from 506 in 1996 to 4,523 in 2003 (Ministry of Labor, 2004). This causes many losses such as compensation costs for medical treatment on the company as well as personal illness and suffering from the WMSDs. It has been known that WMSDs are caused by various risk factors such as poor working posture, mechanical stress, lack of rest, and repetitive manual work. Among these, awkward body posture has been identified as one of the primary causes of WMSDs (Grandjean and Hünting, 1977; Westgaard and Aarås, 1984; Armstrong, 1986; Putz-Anderson, 1988; Armstrong et al., 1993).

For the protection against WMSDs, it is necessary to assess postural stresses quantitatively and to examine its effect to WMSDs. Observational methods such as OWAS (Karhu et al., 1981), RULA (McAtamney and Corlett, 1993), REBA (Hignett and McAtamney, 2000) are widely used to evaluate postural stresses since they are easy to use and they adopt quickly.

These methods have some limitations on the evaluation of working posture with external load. Each method has a different postural classification to measure stress and the results of assessment is explained qualitatively because they are based on limited literatures, case studies, simple biomechanical analyses, or the subjective judgment of experts. Furthermore, they only consider the weight of the external load. It is natural that discomfort increases as the external load increases. However, the effect of the external load on discomfort or postural stress would vary depending on the location of the external load or postures.

It has been reported that WMSDs appear more frequently on the upper limb than on the lower limb (MacLeod, 1999). In many occupational settings of manufacturing, the workers are engaged in tasks that require nonneutral shoulder and elbow postures combined with the external loads. Kee and Karwowski (2001) proposed a classification scheme for evaluating postural stress on the upper body without any external load. Kee (2004) conducted a research related to the evaluation of shoulder and elbow postures with the external loads. However, this study considered only the main effects, using the orthogonal array to reduce the experiment size. Therefore, the evaluation of postural stress on the upper body, particularly on the shoulder and elbow, was not accomplished accurately.

The purpose of this study is to examine and quantify the perceived discomforts of postures which are combined with shoulder flexion/extension and elbow flexion, and added to the external loads. Also, a classification of the effect of external loads on discomfort is proposed based on the experiment results.

\section{Method}

12 healthy male undergraduate and graduate students participated in the experiment. The mean (standard deviation) of their age, height, weight were 25.9 $( \pm 2.5) \mathrm{yr}, 174( \pm 4.1) \mathrm{cm}, 66.8( \pm 6.0) \mathrm{kg}$, respectively. All subjects were right handed.

Independent variables were shoulder posture, elbow posture, and external load. Shoulder postures were flexion/extension angles which the negative angle indicated extension: $-20^{\circ}, 0^{\circ}, 45^{\circ}, 90^{\circ}, 135^{\circ}$. 
Abduction/adduction and internal/external rotation at shoulder joint were not included. Abduction/adduction at the shoulder joints does not have any significant effect to the perceived discomfort (Ryu et al., 2004). Internal/external rotation slightly affects the perceived discomfort and it is difficult to achieve precise control (Kee and Karwowski, 2001). Elbow postures were defined as flexion angles based on Kee and Karwowski (2001): $0^{\circ}, 45^{\circ}, 120^{\circ}$. The levels of external loads were $0.0,1.5 \mathrm{~kg}$, and $3.0 \mathrm{~kg}$. In this study, within subject design was used and 45 conditions were presented randomly to each subject.

Dependent variable was a perceived discomfort. Subjects rated a perceived discomfort using Borg's CR10 (Borg, 1993). Borg's CR10 has a score from 0 to 10 that has a different meaning. For example, 1, 3, 5, 7, and 10 means very weak, moderate, strong, very strong, and extremely strong, respectively. Subjects rated the perceived discomfort after having maintained the given posture for 60 seconds.

\section{Result}

\section{ANOVA results}

Three-way ANOVA was performed (Table 1). Shoulder flexion/extension, elbow flexion, and external loads had an effect on the perceived discomfort significantly $(\alpha=0.05)$. Three interaction effects were appeared to be significant $(\alpha=0.05)$. As the flexion/extension angles of shoulder joint or external loads increased, the perceived discomfort increased (Figure 1,3). The difference of the perceived discomfort between shoulder flexion $90^{\circ}$ and $135^{\circ}$ was not significant $(\alpha=0.05$ ) based on the result of SNK (Student Newman-Keuls) test. As the flexion angles at elbow increased, the perceived discomfort decreased. The perceived discomfort between elbow flexion $0^{\circ}$ and $45^{\circ}$ was not significantly different $(\alpha=0.05)$ (Figure 2$)$.

Table 1. ANOVA table of the whole body discomfort

\begin{tabular}{|c|c|c|c|c|c|}
\hline Sourece & $3{ }^{2}$ & S & 158 & S & I \\
\hline $\begin{array}{c}\text { Shoulder } \\
\text { flexion/extension (S) }\end{array}$ & 4 & 772.4 & 193.1 & 129.7 & $<.0001^{\circ}$ \\
\hline Elbow flexion (E) & 2 & 34.51 & 17.26 & 19.59 & $<.0001^{\circ}$ \\
\hline External loads (EL) & 2 & 1257 & 628.9 & 257.4 & $<.0001^{*}$ \\
\hline$S \times E$ & 8 & 153.4 & 19.18 & 21.16 & $<.0001^{\circ}$ \\
\hline$S \times E L$ & 8 & 92.04 & 11.51 & 15.15 & $<.0001^{\circ}$ \\
\hline$E \times E L$ & 4 & 21.82 & 5.46 & 7.41 & $<.0001^{\circ}$ \\
\hline$S \times E \times E L$ & 16 & 80.85 & 5.05 & 8.09 & $<.0001^{\circ}$ \\
\hline Subject (Sub) & 11 & 139.4 & 12.67 & & \\
\hline Sub $\times S$ & 44 & 65.50 & 1.49 & & \\
\hline Sub $\times E$ & 22 & 19.38 & 0.88 & & \\
\hline Sub $\times E L$ & 22 & 53.76 & 2.44 & & \\
\hline Sub $\times S \times E$ & 88 & 79.79 & 0.91 & & \\
\hline Sub $\times S \times E L$ & 88 & 66.81 & 0.76 & & \\
\hline Sub $\times E \times E L$ & 44 & 32.39 & 0.74 & & \\
\hline Sub $\times S \times E \times E L$ & 176 & 113.0 & 0.64 & & \\
\hline
\end{tabular}

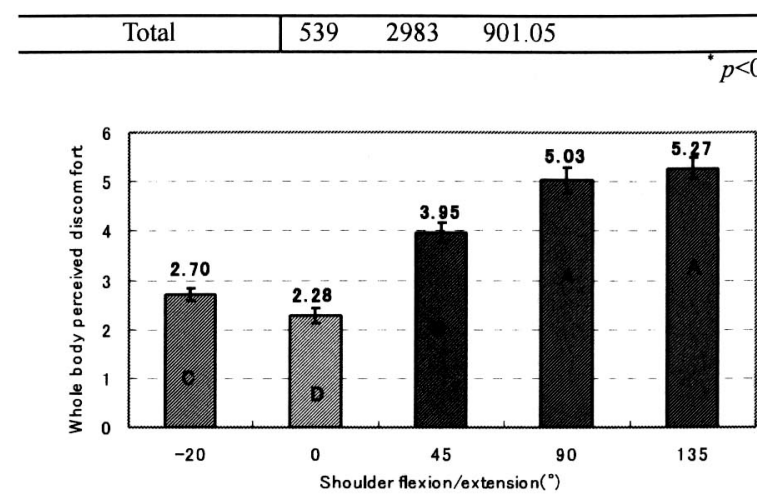

Figure 1. Mean discomfort ratings for shoulder flexion/extension

(alphabet means the SNK test result, $\alpha=0.05$ )

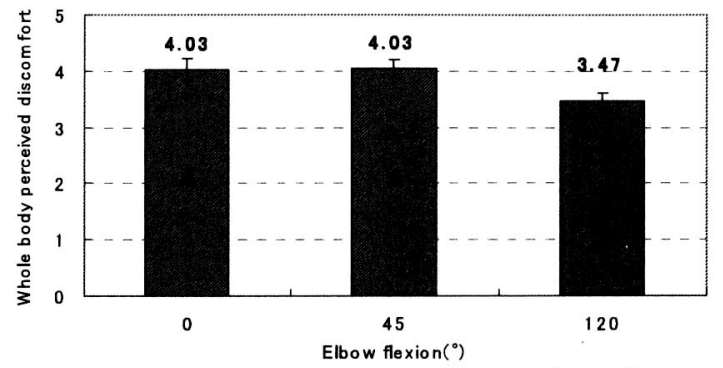

Figure 2. Mean discomfort ratings for elbow flexion (alphabet means the SNK test result, $\alpha=0.05$ )

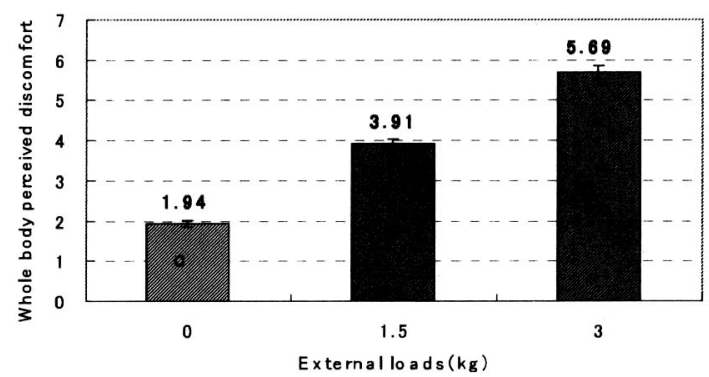

Figure 3. Mean discomfort ratings for external loads (alphabet means the SNK test result, $\alpha=0.05$ )

In the interaction effect of shoulder posture and external loads, the differences of the perceived discomfort between the levels of external loads increased as the shoulder flexion/extension angles increased (Figure 4). The differences of the perceived discomfort between the levels of external loads on shoulder flexion $45^{\circ}$ is larger than that of shoulder flexion $0^{\circ}$. In the interaction effect of elbow posture and external loads, the difference of the perceived discomfort between the levels of external loads at elbow flexion $135^{\circ}$ was smaller than that at the elbow flexion $0^{\circ}$ and $45^{\circ}$ (Figure 5).

A simple effect analysis and SNK test were performed to test the significance of the effect of each level of shoulder and elbow posture to the perceived discomfort. The effect of shoulder and elbow posture on the perceived discomfort was found to be significant 
$(\alpha=0.05)$. The perceived discomfort increased as the shoulder flexion/extension angles increased. In all levels of shoulder posture except for shoulder flexion $0^{\circ}$, the perceived discomfort was decreased as the angles of elbow flexion increased (Figure 6).

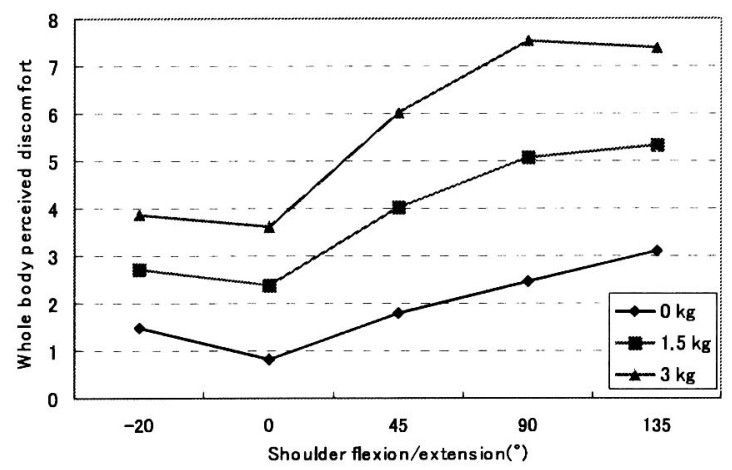

Figure 4. Interaction effect of shoulder posture and external loads

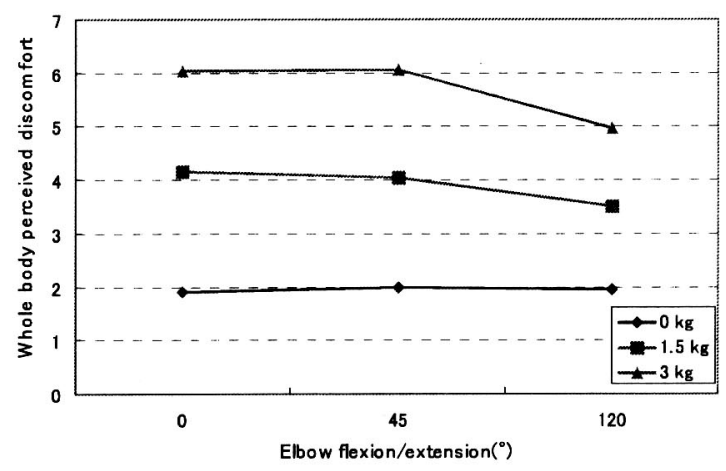

Figure 5. Interaction effect of elbow posture and external loads

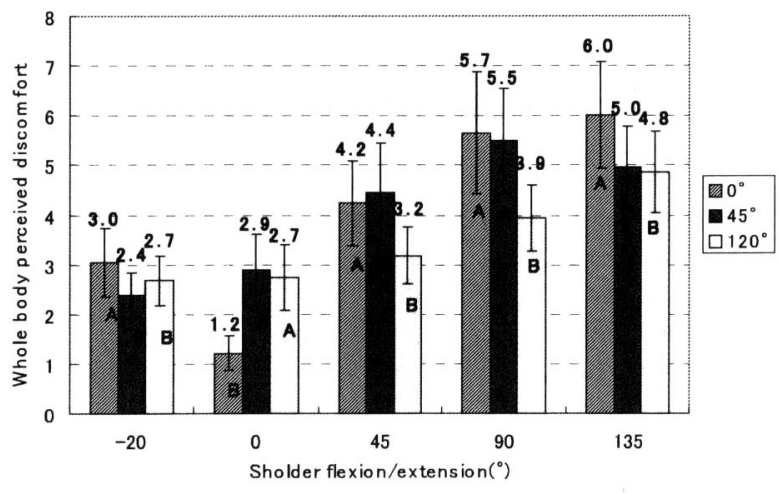

Figure 6. Simple effect of shoulder posture and elbow posture (alphabet means the SNK test result, $\alpha=0.05$ )

\section{Regression results}

Regression analyses were performed based on the external loads as an independent variable and the perceived discomfort as a dependent variable for each posture and subject. From 15 postures combined with 5 levels of shoulder flexion/extension and 3 levels of elbow flexion on 12 subjects, slope and constant of each regression equation were generated. The result of regression analysis showed that $\mathrm{R} 2$ value was over 0.7 in 151 cases out of 180 regression equations. It was found that the perceived discomfort linearly increased as the external loads increased.

One-way ANOVA was performed based on the slopes generated by regression analyses as a dependent variable and 15 postures as an independent variable. The result of ANOVA showed that posture as a main factor was statistically significant $(\alpha=0.05)$ (Table 2$)$. And all postures were classified into six groups based on the result of SNK test (Table 3).

Table 2. ANOVA table of the effect of external loads on each posture

\begin{tabular}{|c|c|c|c|c|c|}
\hline 3 & (t) & 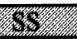 & 1) & 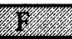 & 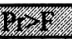 \\
\hline Posture (P) & 14 & 39.52 & 2.82 & 16.21 & $<.01^{*}$ \\
\hline Subject (Sub) & 11 & 9.39 & 0.85 & & \\
\hline Sub $\times P$ & 154 & 26.81 & 0.17 & & \\
\hline Total & 179 & 75.72 & 3.85 & & \\
\hline
\end{tabular}

Table 3. The effect of external loads

\begin{tabular}{|c|c|c|c|c|}
\hline \multicolumn{3}{|c|}{ Posture } & \multirow[b]{2}{*}{$\begin{array}{l}\text { Mean } \\
\text { of slope }\end{array}$} & \multirow[b]{2}{*}{$\begin{array}{c}\text { Grouping } \\
\text { of SNK } \\
\text { test result }\end{array}$} \\
\hline No. & $\begin{array}{l}\text { Shoulder } \\
\text { flexion/ } \\
\text { extension }\end{array}$ & $\begin{array}{l}\text { Elbow } \\
\text { flexion }\end{array}$ & & \\
\hline 1 & $90^{\circ}$ & $0^{\circ}$ & 2.11 & \\
\hline 2 & $90^{\circ}$ & $45^{\circ}$ & 1.95 & \\
\hline 3 & $45^{\circ}$ & $45^{\circ}$ & 1.8 & \\
\hline 4 & $135^{\circ}$ & $0^{\circ}$ & 1.71 & \\
\hline 5 & $45^{\circ}$ & $0^{\circ}$ & 1.5 & \\
\hline 6 & $135^{\circ}$ & $120^{\circ}$ & 1.29 & \\
\hline 7 & $0^{\circ}$ & $45^{\circ}$ & 1.2 & \\
\hline 8 & $135^{\circ}$ & $45^{\circ}$ & 1.17 & \\
\hline 9 & $0^{\circ}$ & $120^{\circ}$ & 1.13 & \\
\hline 10 & $90^{\circ}$ & $120^{\circ}$ & 0.94 & \\
\hline 11 & $45^{\circ}$ & $120^{\circ}$ & 0.93 & \\
\hline 12 & $-20^{\circ}$ & $0^{\circ}$ & 0.89 & \\
\hline 13 & $-20^{\circ}$ & $120^{\circ}$ & 0.81 & \\
\hline 14 & $-20^{\circ}$ & $45^{\circ}$ & 0.69 & \\
\hline 15 & $0^{\circ}$ & $0^{\circ}$ & 0.45 & \\
\hline
\end{tabular}

\section{Discussion and Conclusion}

The result of ANOVA showed that all main factors and three interaction effect were statistically significant $(\alpha=0.05)$. The difference of the perceived discomfort between the levels of external loads at shoulder flexion $135^{\circ}$ was smaller than that at the shoulder flexion in the interaction effect between shoulder flexion/extension and external loads. It showed that the perceived discomfort was affected by the reduction of moment arm when the shoulder flexion changed from $90^{\circ}$ to $135^{\circ}$. In the interaction effect of elbow posture and external loads, as the elbow flexion angles increased, the hand was closer from the body. Then a length of moment arm was reduced, and the perceived discomfort decreased.

In the interaction effect of shoulder 
flexion/extension and elbow flexion, although the moment at $90^{\circ}$ out of shoulder flexion angles had to be the largest value when the elbow flexion was $0^{\circ}$, the perceived discomfort at the shoulder flexion $135^{\circ}$ was larger than that at the shoulder flexion $90^{\circ}$. And, it was also found that the perceived discomfort increased as the shoulder flexion angles changed from $45^{\circ}$ to $135^{\circ}$ when the elbow flexion was $120^{\circ}$. It was estimated that the muscles that are used to work a joint were different according to the flexion/extension angles, and the moment at the joint was not the only factor which had an effect to the perceived discomfort.

In this study, the effect of the external loads on the perceived discomfort was quantified based on grouping the slope of the regression analysis results. The effect of external loads on each posture could be classified as high loads (posture number 1 to 4 ), moderate loads (posture number 5 to 90 , and low loads group (posture number 10 to 15 ) based on the effect of external loads (Table 3). In the high loads group, postures that have the hand far away from the body were mainly composed. Since postural stress decreased when the hand was closer from the body, the effect of external loads decreased from high loads to low loads group. Then, the standardization of the effect of external loads on each group was established (Table 4). The group parameter indicated an average value of mean of slope at each group. The standard numerical figure was obtained by dividing each group parameter by 0.79 to get the smallest value out of three group parameters. High loads, moderate loads, and low loads group were assigned 2.39 , 1.59 , and 1 , respectively.

Table 4. The classification of the effect of external loads

\begin{tabular}{c|c|ccccc}
\hline \multicolumn{2}{c|}{$\begin{array}{c}\text { Postural } \\
\text { classification }\end{array}$} & \multicolumn{5}{c}{ Shoulder posture } \\
\cline { 2 - 7 } Elbow & $0^{\circ}$ & 1 & 1 & 1.59 & 2.39 & 2.39 \\
posture & $45^{\circ}$ & 1 & 1.59 & 2.39 & 2.39 & 1.59 \\
& $135^{\circ}$ & 1 & 1.59 & 1 & 1 & 1.59 \\
\hline
\end{tabular}

This study investigated the effect of external loads to the perceived discomfort on the postures combined with shoulder and elbow, while other studies considered a simple posture such as a shoulder or an elbow, solely. It is possible to understand that the postures that are combined with shoulder and elbow, and added external loads affect the perceived discomfort in this study. And, the effect of external load on discomfort is investigated and classified using the results of the regression analyses.

\section{References}

[1] Armstrong, T.J.:Upper-extremity postures: definition, measurement and control. In: E.N.Corlett, J. Wilson, I.Manenica (Eds.), The ergonomics of working postures. Taylor \& Francis, London:59-73, 1986

[2] Armstrong, T., Punnett, L. and Ketner, P.:Subjective worker assessment of hand tools used in automobile assembly., American Industrial Hygiene Association Journal, 50: 639-645, 1989

[3] Armstrong, T.J., Buckle, P., Fine, L.J., Harberg, M., Jonsson, B., Kilbom, A., Kuorinka, I.A.A., Silverstein, B.A., Sjogaard, G. and Viikari-Juntura, E.R.A.:A conceptual model for work-related neck and upper-limb musculoskeletal disorders., Scandinavian J. Work, Environment and Health, 19(2):73-84, 1993

[4] Borg, G. Borg's perceived exertion and pain scales, Human Kinetics, Champaign (IL),1993

[5] Grandjean, E. and Hünting, W.:Ergonomics of postures - review of various problems of standing and sitting postures., Applied Ergonomics, 8(3):135-140, 1977

[6] Hignett, S. and McAtamney, L.:Rapid entire body assessment (REBA)., Applied Ergonomics,

31(2):201-205, 2000

[7] Karhu, O., Hrknen, R., Sorvali, P. and Vepslinen, P.:Observing working postures in industry: Examples of OWAS application., Applied Ergonomics, 12(1):13-17, 1981

[8] Kee, D.:Investigation on perceived discomfort depending on external load, upper limb posture and their duration., J. the Korean Institute of Industrial Engineers, 30(2):76-83, 2004

[9] Kee, D. and Karwowski, W.:LUBA: an assessment technique for postural loading on the upper body based on joint motion discomfort and maximum holding time., Applied Ergonomics, 32(4):357-366, 2001

[10] MacLeod, D.:The office ergonomics kit. Lewis Publishers, New York: 1999

[11] McAtamney, L. and Corlett, E. N.:RULA: a survey method for the investigation of work-related upper limb disorders., Applied Ergonomics, 24(2):91-99, 1993

[12] Putz-Anderson, V.:Cumulative trauma disorders: A manual for musculoskeletal diseases of the upper limbs. Taylor \& Francis, London: 1988

[13] Ryu, T., Park, Y., Na, S., Chung, M.K., and Kee, D.:Evaluation of varying shoulder postures with external loads using a psychophysical method., J. the Ergonomics Society of Korea, 24(2):9-15, 2005 [14] Westgaard, R.H. and Aarås, A.:Postural muscle strain as a casual factor in the development of musculoskeletal illnesses., Applied Ergonomics, 15(3):162-174, 1984. 